\title{
Perbandingan Watermarking Citra dengan Alihragam Wavelet dan Discrete Cosine Transform
}

\author{
B. Yudi Dwiandiyanta \\ Program Studi Teknik Informatika, Universitas Atma Jaya Yogyakarta \\ Jl. Babarsari No. 43, Yogyakarta 55281, Indonesia \\ E-mail: yudi-dwi@mail.uajy.ac.id
}

\begin{abstract}
Comparison of Image Watermarking with the Wavelet Variety Packs and Discrete Cosine Transform. Watermarking is one method of copyright protection to combat the spread of the work of someone illegally. In this study, we compare watermarking algorithm in wavelet region and Discrete Cosine Transform (DCT). Color image is used as the host image, while the watermark image is used as a binary image of size $1 / 16$ image of the host. Embedding process is based on Human Visual System (HVS), so hopefully gained an invisible watermark (invisible watermark). Embedding process performed by the additive algorithm. In both variety packs developed, the watermark is inserted in the high frequency components of the image. Wavelet used is the wavelet db4. DCT $4 \times 4$ blocks are used, which is expected to reduce the computational load. Tests showed that the two watermarking algorithms are generally resistant to granting noise, geometric image operations and image processing operations. Watermarking algorithm that was developed less defend against attacks-down pass filter and median filter, but has a very good performance against an attack-pass filter above.
\end{abstract}

Keywords: image watermarking, wavelet, Discrete Cosine Transform (DCT), Human Visual System (HVS)

\begin{abstract}
Abstrak. Watermarking merupakan salah satu metode proteksi hak cipta untuk menanggulangi penyebaran karya seseorang secara ilegal. Pada penelitian ini dilakukan perbandingan algoritma watermarking pada kawasan wavelet dan Discrete Cosine Transform (DCT). Citra warna digunakan sebagai citra host, sedangkan sebagai citra watermark digunakan citra biner berukuran 1/16 citra host. Proses embedding dilakukan berdasarkan Human Visual System (HVS), sehingga diharapkan diperoleh watermark yang tidak kelihatan (invisible watermark). Proses embedding dilakukan dengan algoritma aditif. Pada kedua alihragam yang dikembangkan, watermark disisipkan pada komponen frekuensi tinggi citra. Wavelet yang digunakan adalah wavelet $\mathrm{db} 4$. Sedangkan alihragam DCT yang digunakan adalah operasi blok $4 \times 4$, yang diharapkan dapat mengurangi beban komputasi. Pengujian menunjukkan bahwa kedua algoritma watermarking secara umum tahan terhadap pemberian derau, operasi geometris citra dan operasi-operasi pengolahan citra. Algoritma watermarking yang dikembangkan kurang bertahan terhadap serangan-serangan tapis lolos-bawah dan tapis median, namun mempunyai unjuk kerja yang sangat baik terhadap serangan tapis lolos-atas.
\end{abstract}

Kata Kunci: watermarking citra, wavelet, Discrete Cosine Transform (DCT), Human Visual System (HVS)

\section{Pendahuluan}

Dewasa ini perkembangan teknik pengolahan citra sudah sangat pesat. Perkembangan 
itu didukung pula oleh komputer dengan kapasitas memori yang besar, sehingga memungkinkan untuk melakukan komputasi dalam waktu yang relatif singkat. Banyak aplikasi yang terdapat dalam teknik pengolahan citra, diantaranya adalah peningkatan citra (image enhancement), pemulihan citra (image restoration), analisis citra (image analysis), sistem kompresi data citra (image compression), dan sistem keamanan data citra.

Diantara sekian banyak aplikasi pengolahan citra, bidang yang banyak menarik perhatian adalah sistem keamanan data citra. Metode pengamanan data yang telah banyak dilakukan antara lain adalah steganografi, enkripsi, dan fingerprint. Saat ini, seiring dengan berkembangnya teknologi informasi, publikasi elektronik, dan sistem distribusi video/citra digital melalui internet, maka diperlukan suatu teknik yang dapat digunakan untuk melakukan proteksi terhadap hak cipta. Watermarking merupakan salah satu metode proteksi hak cipta yang bertujuan untuk menanggulangi penyebaran karya seseorang secara ilegal. Pada dasarnya, watermarking adalah proses penandaan suatu citra dengan pesan hak cipta atau signature yang secara rahasia disisipkan dalam citra namun tidak terlihat perbedaan antara citra asli dengan citra yang telah ditandai. Pesan hak cipta yang disisipkan dapat berupa nomor register (seperti UPC: Universal Producer Number) yang sering dijumpai dalam CD, pesan teks, gambar atau logo perusahaan, citra tanda tangan atau sidik jari seseorang ataupun citra foto seseorang.

Teknik watermarking yang berkembang saat ini masih memiliki kekurangan dalam hal ketahanan terhadap operasi-operasi pengolahan citra (misalnya penapisan, operasi modifikasi aras keabuan), ketahanan terhadap serangan derau, ketahanan terhadap operasi-operasi geometris (misalnya pemotongan, penyekalaan dan rotasi citra), dan ketahanan terhadap operasi kompresi citra.

\section{Tinjauan Pustaka}

Istilah steganografi atau menyembunyikan informasi sejarahnya telah dimulai sejak jaman Yunani kuno ketika seorang raja hendak mengirimkan pesan rahasia yang harus melewati daerah musuh. Raja tersebut memanggil budak kepercayaannya untuk kemudian mentato pesannya diatas kulit kepala. Begitu rambut budak tersebut tumbuh, budak tersebut kemudian dikirim hingga ke tujuannya. Teknik demikian terus berkembang hingga pada abad ke-20, ketika tentara Jerman menyembunyikan informasi dengan cara menulis pesan dengan tinta yang tidak bisa dilihat. Begitu sampai di tujuan, pesan tersebut diolah sedemikian rupa hingga tulisannya muncul.

Saat ini, seiring dengan kemajuan komputer, teknik steganografi berkembang ke arah bentuk menempelkan logo dalam informasi yang dapat dilihat (watermarking tampak), atau logo yang tidak dapat dilihat (watermarking tidak tampak) yang disimpan dalam citra digital. Watermarking dapat digunakan sebagai bukti kepemilikan dalam persidangan (Langelaar, 2000).

Berdasarkan kawasan penyisipan watermark, terdapat dua cara untuk melakukan watermarking, yaitu watermarking pada kawasan spasial dan watermarking pada kawasan frekuensi (Meerwald, 2001). Watermarking pada kawasan spasial [3, 4, 5, 6] mudah diimplementasikan dan tidak memerlukan citra asli (host) untuk mendeteksi watermark. Keunggulan penggunaan watermarking pada kawasan spasial adalah beban komputasi yang relatif lebih sedikit, sehingga dapat diimplementasikan untuk aplikasi real time. Kelemahan penggunaan watermarking pada kawasan spasial adalah kegagalan untuk mendeteksi watermark apabila citra telah diolah misalnya dengan penapisan, operasi geometris (cropping, penyekalaan citra), dan kompresi. Kelemahan yang lain adalah terjadinya penurunan kualitas citra karena watermarking diterapkan langsung pada piksel citra (Wang, 1998).

Watermarking pada kawasan frekuensi dapat dilakukan pada kawasan Discrete Cosine Transform (DCT), Discrete Fourier Transform (DFT), dan Discrete Wavelet Transform (DWT). Cox et al. (Cox, 1997) dan Koch et al. (Koch, 1994) telah melakukan penelitian watermarking yang dilakukan pada kawasan DCT. Ramkumar et al. (Ramkumar, 1999) melakukan penelitian watermarking yang dilakukan pada kawasan DFT. Penelitian watermarking pada kawasan 
DWT telah banyak dilakukan. Penggunaan keluarga wavelet Daubechies dan kode Hamming membuat citra yang telah disisipi watermark lebih tampak seperti aslinya (Wang, 1998). Kanai et al. (Kanai, 1998) menggunakan citra poligon sebagai citra host, sehingga dapat digunakan untuk melakukan proteksi hak cipta terhadap model-model geometris 3-dimensi. Pereira et al. (Pereira, 1999) menitikberatkan pada optimisasi proses embedding dengan menggunakan linear programming. Watermarking pada kawasan DWT dapat juga dilakukan dengan menggabungkan dengan algoritma kompresi HS (Hierarchical Segmentation) dan menggunakan citra medis ROI (Region of Interest) sebagai citra host (Wakatani, 2002). Watermarking dapat digunakan untuk tujuan image authentication dengan menggunakan teknik kuantisasi optimal (Paquet, 2002).

Watermarking pada kawasan frekuensi secara umum memberikan perlindungan yang lebih terhadap pengolahan terhadap citra yang telah disisipi watermark (Meerwald, 2001). Akan tetapi watermark pada kawasan frekuensi umumnya membutuhkan citra asli (host) untuk mendeteksi watermark.

Diantara ketiga jenis kawasan transformasi tersebut, kawasan DWT memiliki kelebihan dalam hal ketelitian analisis terhadap isyarat transformasi (Meerwald, 2001). Koefisien transformasi hasil DWT selanjutnya digabungkan dengan data watermark yang telah dipersiapkan guna penggabungan.

Pada penelitian ini akan dilakukan perbandingan algoritma watermarking yang dilakukan pada kawasan wavelet dan DCT. Diharapkan akan diperoleh perbandingan kedua algoritma terhadap operasi-operasi pengolahan citra, serangan derau, operasi-operasi geometris citra. Proses embedding pada kawasan wavelet dan DCT dilakukan berdasarkan Human Visual System (HVS) dengan obyek berupa citra warna, sehingga diharapkan diperoleh watermark yang tidak kelihatan (invisible watermark).

\subsection{Alihragam Wavelet}

Alihragam wavelet mempunyai penerapan yang luas pada aplikasi pengolahan isyarat dan pengolahan citra. Ide dasar alihragam Discrete Wavelet Transform (DWT) 1-dimensi adalah seperti berikut. Isyarat dibagi menjadi dua bagian, frekuensi tinggi dan frekuensi rendah. Bagian frekuensi rendah dibagi lagi menjadi isyarat frekuensi tinggi dan rekuensi rendah. Proses ini diulang sampai isyarat tidak dapat didekomposisikan lagi atau sampai pada level yang telah ditentukan pengguna. Beberapa aplikasi pengolahan citra secara umum tidak memerlukan lebih dari 5 level dekomposisi (Meerwald, 2001). Isyarat asli dapat dipulihkan dengan menerapkan invers DWT (IDWT) pada isyarat yang telah didekomposisi.

Secara matematis, DWT dan IDWT dapat dijelaskan seperti berikut. Diberikan tapis lolos-bawah $H(\omega)$, dengan

$$
H(\omega)=\sum_{k} h_{k} e^{-j k \omega}
$$

dan tapis lolos-atas $G(\omega)$, dengan

$$
G(\omega)=\sum_{k} g_{k} e^{-j k \omega}
$$

Isyarat $F(n)$ dapat didekomposisi secara rekursif sebagai

$$
f_{j-1}^{l o w}(k)=\sum_{n} h_{n-2 k} f_{j}(n)
$$

dan

$$
f_{j-1}^{h i g h}(k)=\sum_{n} g_{n-2 k} f_{j}(n)
$$

dengan $j=J+1, J, \ldots J_{0}$ dan $f_{J+1}(k)=F(f), k \in Z$. J+1 adalah indeks resolusi tertinggi dan 
$\mathrm{J}_{0}$ adalah indeks level resolusi terendah. Koefisien

$$
f_{J_{0}}^{l o w}(k), f_{J_{0}}^{h i g h}(k), f_{J_{0}+1}^{h i g h}(k), \ldots, f_{J}^{h i g h}(k)
$$

disebut dengan DWT atas isyarat $\mathrm{F}(\mathrm{n})$, dengan $f_{J_{0}}^{\text {low }}(k)$ adalah resolusi terendah (aproximation) dan $f_{j}^{\text {high }}(k)$ adalah detail isyarat pada tiap bidang frekuensi. Isyarat $\mathrm{F}(\mathrm{n})$ dapat direkonstruksi berdasarkan koefisien DWT secara rekursif dengan

$$
f_{j}^{l o w}(n)=\sum_{k} h_{n-2 k} f_{j-1}^{l o w}(k)+\sum_{k} g_{n-2 k} f_{j-1}^{h i g h}(k)
$$

Pada DWT dan IDWT diperlukan kondisi ortogonal antara tapis $H(\omega)$ dan $G(\omega)$, sehingga

$$
|H(\omega)|^{2}+|G(\omega)|^{2}=1
$$

Sebagai contoh $H(\omega)$ dan $G(\omega)$ diberikan sebagai

$$
H(\omega)=\frac{1}{2}+\frac{1}{2} e^{-j \omega}
$$

dan

$$
G(\omega)=\frac{1}{2}-\frac{1}{2} e^{-j \omega}
$$

yang sering disebut dengan tapis wavelet Haar. Tapis lain yang sering digunakan dalam pengolahan citra adalah keluarga Daubechies (D-4, D-6, D-8, D-10, D-12) dan tapis biortogonal (B-5/3, B-7/9).

DWT dan IDWT isyarat 2-dimensi $\mathrm{F}(\mathrm{m}, \mathrm{n})$ dapat diperoleh dengan menerapkan DWT dan IDWT 1-dimensi pada tiap dimensi $m$ dan $n$ secara terpisah, sehingga menghasilkan struktur piramid seperti terlihat pada contoh pada Gambar 1.

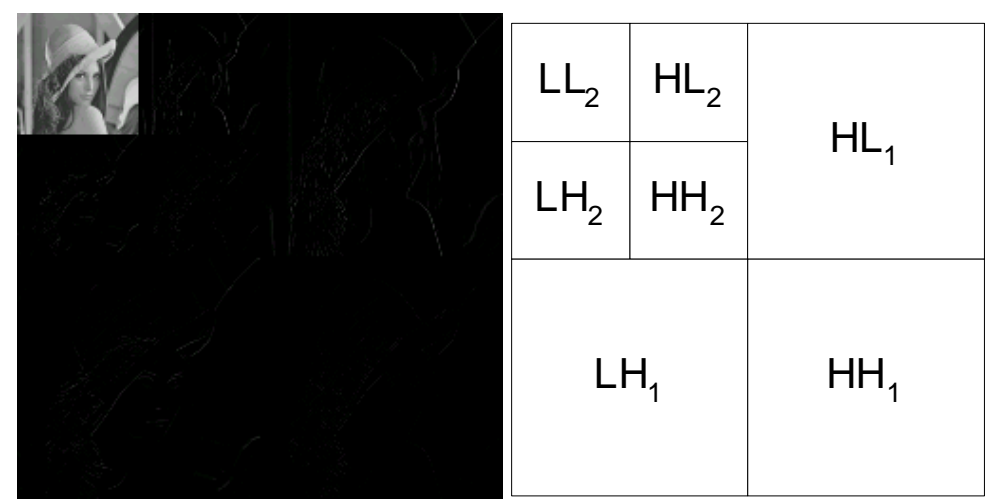

Gambar 1. Contoh Dekomposisi Citra.

\subsection{Discrete Cosine Transform (DCT)}

Discrete Cosine Transform merukan salah satu jenis transformasi yang sering digunakan dalam pengolahan citra. DCT pada dasarnya akan merepresentasikan suatu citra menjadi jumlahan dari gelombang sinusoidal yang berbeda frekuensi dan magnitudo. Transformasi DCT banyak digunakan terutama dalam kompresi citra. Transformasi ini digunakan sebagai dasar pengembangan kompresi JPEG yang digunakan dewasa ini. Alihragam DCT dirumuskan sebagai: 


$$
\begin{aligned}
& \operatorname{DCT}(i, j)=\frac{1}{\sqrt{2 N}} C(i) C(j) \sum_{x=0}^{N-1} \sum_{y=0}^{N-1} \operatorname{pixel}(x, y) \operatorname{Cos}\left[\frac{(2 x+1) i \pi}{2 N}\right] \operatorname{Cos}\left[\frac{(2 y+1) j \pi}{2 N}\right] \\
& C(x)=\left\{\begin{array}{lll}
\frac{1}{\sqrt{2}} & \text { jika } & x=0 \\
1 & \text { jika } & x>0
\end{array}\right.
\end{aligned}
$$

\subsection{Watermarking pada Citra}

Watermarking citra merupakan suatu cara untuk menanamkan data watermark pada suatu citra host. Dalam penelitian ini digunakan beberapa istilah seperti terlihat pada Tabel 1.

Tabel 1. Istilah dalam proses watermarking

\begin{tabular}{ll}
\hline Istilah & Keterangan \\
\hline Citra host & Citra asli yang akan disisipi pesan hak cipta/signature \\
\hline Citra watermark & Citra yang berupa pesan hak cipta/signature \\
\hline Citra stego & Citra host yang telah disisipi dengan pesan hak cipta/signature \\
\hline Embedding & Proses penyisipan citra watermark dalam citra host \\
\hline Ekstraksi & Proses penguraian citra watermark atas citra stego \\
\hline
\end{tabular}

\subsubsection{Embedding dengan Algoritma Aditif}

Pada watermarking dengan algoritma aditif, data watermark disisipkan ke dalam citra host dengan menggunakan persamaan:

$$
f^{\prime}(m, n)=f(m, n)\left(1+\alpha w_{i}\right)
$$

dengan $f^{\prime}(m, n)$ adalah koefisien data host yang sudah dimodifikasi, $\alpha$ adalah faktor embedding strength, $f(m, n)$ adalah koefisien citra host, dan $w_{i}$ adalah citra watermark. Alternatif yang lain, embedding dapat dilakukan dengan menggunakan persamaan:

$$
f^{\prime}(m, n)=f(m, n)+\alpha w_{i}
$$

Ekstraksi watermark dapat dilakukan dengan menggunakan informasi citra host dan informasi citra stego yang ada. Ekstraksi dapat dilakukan dengan menggunakan persamaan:

$$
w_{i}^{*}=\frac{f^{*}(m, n)-f(m, n)}{\alpha f(m, n)}
$$

dengan $w_{i}^{*}$ adalah citra watermark hasil ekstraksi dan $f^{*}(m, n)$ adalah citra yang diterima.

\section{Hasil Penelitian}

Pada simulasi komputer digunakan citra host berupa citra warna dengan ukuran $512 \times 512$ dan citra watermark berupa citra biner dengan ukuran $128 \times 128$. Penggunaan citra biner sebagai watermark karena citra biner umumnya berukuran kecil dan dapat dengan mudah disisipkan ke citra host secara tak terlihat. Informasi mengenai logo perusahaan, logo universitas, tandatangan, ataupun barcode sudah sangat mencukupi jika direpresentasikan menggunakan citra biner.

Citra biner juga lebih tahan terhadap serangan yang ingin melemahkan atau membuang watermark. Citra biner yang mengalami kehilangan informasi, secara pola masih dapat dikenali. 
Berbeda kalau digunakan teks sebagai watermark, perubahan yang terjadi hanya pada satu bit teks akan mengubah informasi watermark secara signifikan. Beberapa contoh hasil penelitian dapat dilihat pada Tabel 2 dan Tabel 3.

Tabel 2. Contoh Hasil Watermarking menggunakan Alihragam Wavelet.

\begin{tabular}{|c|c|c|}
\hline Jenis Serangan & Citra Stego & $\begin{array}{l}\text { Citra Watermark } \\
\text { Hasil Ekstraksi }\end{array}$ \\
\hline Derau Salt and Pepper dengan densitas 0,01 & & \\
\hline Derau Gaussian dengan varians derau 0,005 & & \\
\hline Pemotongan sebesar $25 \%$ & & \\
\hline Tapis Lolos-Atas & & \\
\hline Perubahan nilai brightness sebesar +50 & & \\
\hline $\begin{array}{l}\text { Perentangan Kontras menggunakan Histogram } \\
\text { Equalization }\end{array}$ & & now \\
\hline
\end{tabular}


Tabel 3. Contoh Hasil Watermarking menggunakan Alihragam DCT.

\begin{tabular}{|c|c|c|}
\hline Jenis Serangan & Citra Stego & $\begin{array}{l}\text { Citra Watermark } \\
\text { Hasil Ekstraksi }\end{array}$ \\
\hline Derau Salt and Pepper dengan densitas 0,01 & & \\
\hline Derau Gaussian dengan varians derau 0,005 & & \\
\hline Pemotongan sebesar $25 \%$ & & \\
\hline Tapis Lolos-Atas & & \\
\hline Perubahan nilai brightness sebesar +5 & & \\
\hline $\begin{array}{l}\text { Perentangan Kontras menggunakan Histogram } \\
\text { Equalization }\end{array}$ & & \\
\hline
\end{tabular}

\section{Pembahasan}

Berdasarkan penelitian yang dilakukan, terdapat beberapa persamaan karakteristik antara strategi embedding yang dilakukan pada subbidang detail citra wavelet dan DCT. Berdasarkan grafik pada Gambar 2, embedding yang dilakukan pada kawasan wavelet lebih kebal terhadap derau salt and pepper. Sebaliknya (Gambar 3) embedding dilakukan pada kawasan DCT lebih kebal terhadap derau Gaussian. Jumlah level dekomposisi akan 
berpengaruh terhadap ketahanan sistem watermarking terhadap derau Gaussian dan salt and pepper. Pada embedding yang dilakukan pada subbidang detail citra, pemilihan embedding strength dapat dipilih dengan nilai yang lebih besar, sehingga diperoleh watermarking yang lebih tahan terhadap serangan derau.

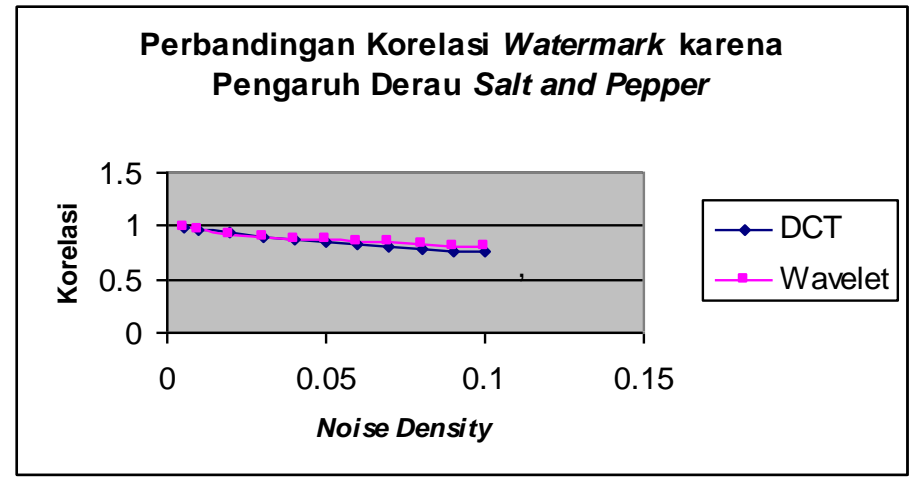

Gambar 2. Grafik perbandingan korelasi watermark embedding pada kawasan wavelet dan DCT karena pengaruh derau salt and pepper.

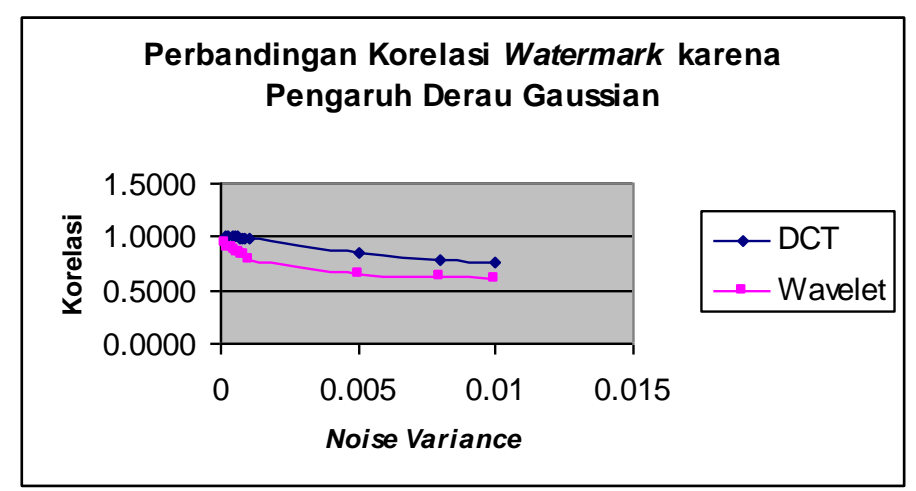

Gambar 3. Grafik perbandingan korelasi watermark embedding pada kawasan wavelet dan DCT karena pengaruh derau Gaussian.

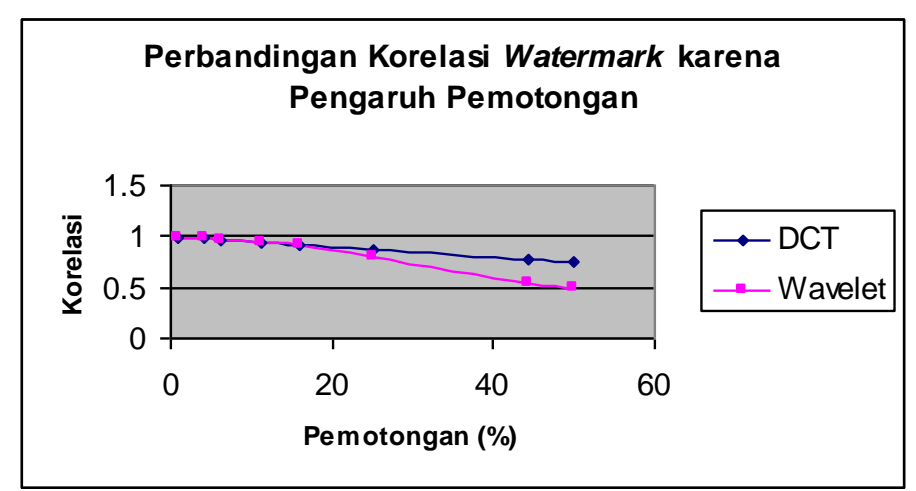

Gambar 4. Grafik perbandingan korelasi watermark embedding pada kawasan wavelet dan DCT karena pengaruh pemotongan citra.

Berdasarkan Gambar 4, terlihat bahwa semakin besar pemotongan citra maka akan semakin kecil korelasi watermark yang diperoleh. Hal ini disebabkan proses pemotongan citra akan menghilangkan informasi watermark yang ada. Pada embedding yang dilakukan pada subbidang detail citra, pemotongan yang dilakukan pada daerah yang halus akan menghasilkan korelasi watermark yang lebih baik dibandingkan pemotongan yang dilakukan pada daerah yang tajam/detail citra. Hal ini disebabkan sifat embedding yang dilakukan pada frekuensi tinggi 
akan menyembunyikan informasi watermark pada detail citra. Jika pemotongan dilakukan pada detail citra, maka akan banyak menghilangkan informasi watermark, sehingga diperoleh korelasi watermark yang lebih rendah.

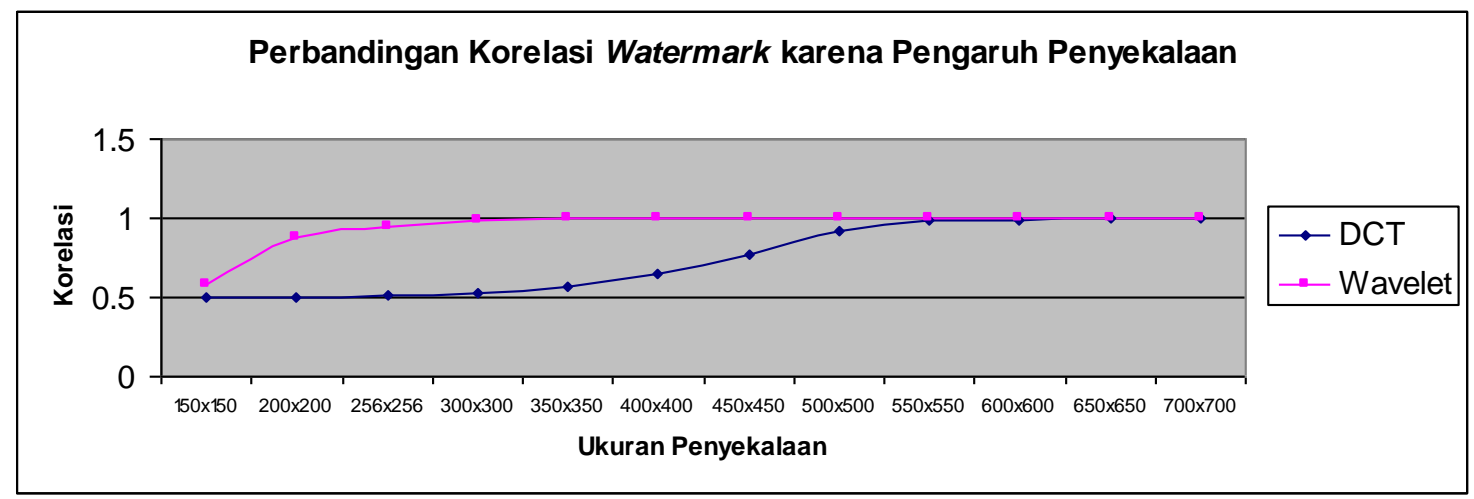

Gambar 5. Grafik perbandingan korelasi watermark embedding pada kawasan wavelet dan DCT karena pengaruh penyekalaan citra.

Berdasarkan Gambar 5, terlihat bahwa semakin besar perbedaan ukuran penyekalaan terhadap citra asli maka akan semakin kecil korelasi watermark yang diperoleh. Hal ini disebabkan proses penyekalaan akan menghilangkan informasi watermark yang ada. Terhadap penyekalaan citra, terlihat penyisipan pada kawasan wavelet lebih unggul dibandingkan dengan penyisipan yang dilakukan pada kawasan DCT.

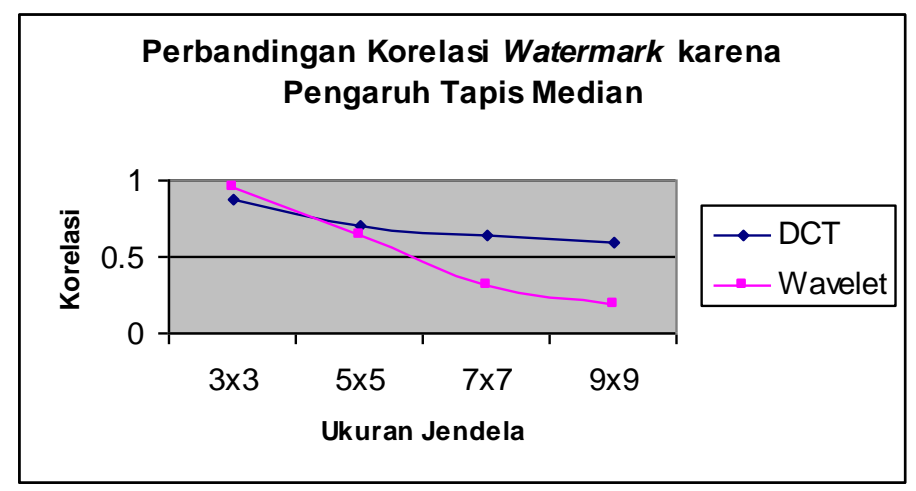

Gambar 6. Grafik perbandingan korelasi watermark embedding pada kawasan wavelet dan DCT karena pengaruh tapis median.

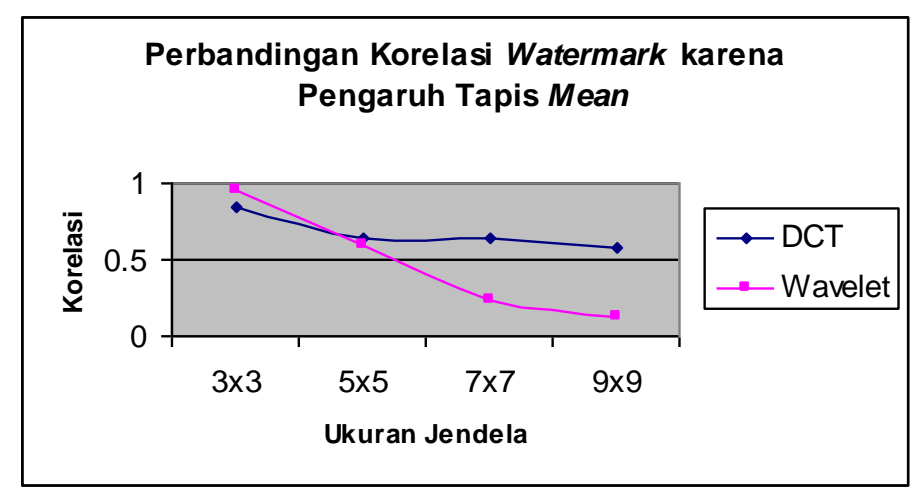

Gambar 7. Grafik perbandingan korelasi watermark embedding pada kawasan wavelet dan DCT karena pengaruh tapis mean. 
Berdasarkan grafik pada Gambar 6 dan 7, embedding yang dilakukan pada kawasan DCT lebih kebal terhadap serangan tapis mean dan tapis median. Rendahnya nilai korelasi watermark disebabkan penyisipan watermark dilakukan pada frekuensi tinggi atau bagian detail citra, sedangkan sifat tapis median adalah menghaluskan citra atau menghilangkan titik-titik yang terisolasi yang kebanyakan mengkontribusikan komponen frekuensi tinggi citra. Dengan berkurangnya komponen frekuensi tinggi citra, maka informasi watermark yang disisipkan pada kawasan frekuensi tinggi citra secara otomatis akan berkurang juga.

\section{Kesimpulan}

Operasi-operasi pengolahan citra (penapisan, perubahan brightness dan penyamaan histogram) akan menyebabkan turunnya nilai korelasi watermark yang diurai. Watermarking citra yang dilakukan dengan alihragam wavelet dan DCT mempunyai keunggulan lebih kebal terhadap serangan-serangan tapis lolos-atas, perubahan brightness dan penyamaan histogram, namun kurang dapat bertahan terhadap serangan-serangan tapis lolos-bawah dan tapis median.

Pemberian derau terhadap citra stego akan menyebabkan turunnya nilai korelasi watermark yang diurai. Semakin banyak derau akan semakin turun nilai korelasi watermark yang diperoleh. Embedding yang dilakukan pada kawasan wavelet lebih kebal terhadap derau salt and pepper. Sebaliknya embedding dilakukan pada kawasan DCT lebih kebal terhadap derau Gaussian.

Proses pemotongan dan penyekalaan citra akan menyebabkan turunnya nilai korelasi watermark yang diurai. Semakin besar pemotongan citra maka akan semakin turun nilai korelasi watermark yang diperoleh. Semakin berbeda ukuran penyekalaan terhadap ukuran citra asli maka nilai korelasi watermark yang diperoleh juga akan semakin turun. Terhadap penyekalaan citra, terlihat penyisipan pada kawasan wavelet lebih unggul dibandingkan dengan penyisipan yang dilakukan pada kawasan DCT.

\section{Referensi}

Langelaar, G.C., 2000, Real Time Watermarking Techniques for Compressed Video Data, Master Thesis, Delft University of Technology, Universal Press, Veenendaal.

Meerwald, P., 2001, Digital Image Watermarking in the Wavelet Transform Domain, Master Thesis, Computer Science, University of Salzburg, Austria.

Tirkel, A.Z., C.F. Osborne, and R.G. Schyndel, 1996, Image Watermarking a Spread Spectrum Technique, IEEE $4^{\text {th }}$ International Symposium on Spread Spectrum Techniques and Applications, Vol. II, pp. 785-789.

Yeung, M.M. and F. Mintzer, 1997, An Invisible Watermarking Techniques for Image Verification, IEEE International Conference on Image Processing (ICIP 1997), Vol. II, pp. 680-683.

Bartollini, F., A. Tefas, M. Barni, and I. Pitas, 2001, Image Authentication Techniques for Surveillance Application, Proceedings of the IEEE, Vol. 89, No. 10, pp. 1403-1418.

Queluz, M.P. and P. Lamy, 2000, Spatial Watermark for Image Verification, SPIE Conference on security and Watermarking of Multimedia Contents II, Vol. 3971, pp. 120-130.

Wang, Houng-Jyh Mike, Su, Po-Chyi and C. Jay Kuo, 1998, Wavelet-based Digital Image Watermarking, Department of Electrical Engineering-Systems University of Southern California, Los Angeles.

Cox, I.J., J. Kilian, F.T. Leighton, and T. Shamoon, 1997, Secure Spread Spectrum Watermarking for Multimedia, IEEE Transaction on Image Processing, Vol. 6, No. 12, pp. 1673-1687.

Koch, E., J. Rindfrey, and J. Zhao, 1994, Copyright Protection for Multimedia Data, Proc. Int. Conf. Digital Media and Electronic Publishing.

Ramkumar, M., A.N. Akansu, and A.A. Alatan, 1999, A Robust Data Hiding Scheme for 
Images Using DFT, in Proceedings of the $6^{\text {th }}$ IEEE International Conference on Image Processing ICIP 99, pp. 211-215.

Kanai, S., H. Date, and T. Kishinami, 1998, Digital Watermarking for 3D Polygon using Multiresolution Wavelet Decomposition, Department of Systems Engineering, Hokkaido University, Sapporo, Japan.

Pereira, S., S. Voloshynovskiy, and T. Pun, 1999, Optimized Wavelet Domain Watermark Embedding Strategy Using Linear Programming, University of Geneva - CUI, Geneva, Switzerland.

Wakatani, Akiyoshi, 2002, Digital Watermarking for ROI Medical Images by using Compressed Signature Image, Proceedings of the $35^{\text {th }}$ Hawai International Conference on System Sciences.

Paquet, A.H. and R.K. Ward, 2002, Wavelet Based Digital Watermarking for Image Authentication, University of British Columbia, Department of Electrical and Computer Engineering, Canada. 